УДК 615.017

\title{
ОЦЕНКА IN VITRO ВОЗМОЖНОГО ЦИТОТОКСИЧЕСКОГО ДЕЙСТВИЯ ГЛИЦИРРИЗИНОВОЙ КИСЛОТЫ ПРИ ИНТРАНАЗАЛЬНОМ ВВЕДЕНИИ
}

\author{
Боева Ольга Сергеевна \\ Быкова Мария Владимировна
} студенты

Институт медицины и психологии В. Зельмана НГУ Научный руководитель: Пашкина Екатерина Александровна к.б.н., старший научный сотрудник ФГБНУ «НИИ фундаментальной и клинической иммунологии»

Аннотация: Известно, что глицирризиновая кислота обладает противовоспалительным и иммуномодулирующим действием, в том числе и при применении на слизистых оболочках. Кроме того, в настоящее время имеются данные о создании супрамолекулярных комплексов на основе глицирризиновой кислоты и ее производных с различными препаратами для осуществления лекарственной доставки. В связи с вышесказанным, представляет научный интерес изучение свойств глицирризиновой кислоты для применения в качестве основы для лекарственной доставки при интерназальном введении.

Ключевые слова: глицирризиновая кислота, интраназальное введение, система лекарственной доставки, цитотоксичность, иммунокомпетентные клетки.

\section{IN VITRO ASSESSMENT OF THE POSSIBLE CYTOTOXIC EFFECT OF GLYCYRRISIC ACID WITH INTRANASAL ADMINISTRATION}

\section{Boeva Olga Sergeevna Bykova Maria Vladimirovna Pashkina Ekaterina Aleksandrovna}

Abstract: It is known that glycyrrhizic acid has anti-inflammatory and immunomodulatory effects, including when used on mucous membranes. In 
addition, there are currently data on the creation of supramolecular complexes based on glycyrrhizic acid and its derivatives with various drugs for drug delivery. In connection with the above, it is of scientific interest to study the properties of glycyrrhizic acid for use as a basis for drug delivery when administered internally.

Key words: glycyrrhizic acid, intranasal administration, drug delivery system, cytotoxicity, immunocompetent cells.

Согласно литературным источникам, глицирризиновая кислота, основной биоактивный гликозид корня солодки, обладает широким спектром фармакологических свойств, в том числе и противовоспалительным действием, а также способствует отхождению мокроты, благодаря чему препараты на основе солодки успешно применяются для терапии таких заболеваний, как бронхиальная астма и аллергический ринит [1-3]. Также в последнее десятилетие было обнаружено, что глицирризиновая кислота и ее производные обладают противовоспалительным и выраженным противоаллергическим действием, благодаря чему использование данных веществ в комплексной терапии иммунопатологий (прежде всего аллергии) становится весьма актуальным [4-9]. Кроме того, известно, что глицирризиновая кислота и ее производные обладают способностью образовывать межмолекулярные комплексы и мицеллы, включающие лекарственные молекулы с целью адресной доставки лекарственных средств [10].

В первую очередь нами было исследовано влияние самой системы доставки, глицирризиновой кислоты (ГК), на токсичность по отношению к различным типам клеток, способным иметь значение при интерназальном введении, а именно клетки полости носа и иммунокомпетентные клетки. Для этого оценивалось влияние на клетки линии RPMI 2650 (назальная карцинома полости носа, стандартная клеточная линия для создания модели для оценки проникновения препаратов через слизистую носа), влияние ГК на данную клеточную линию исследуется впервые, а также первичная культура клеток мононуклеарных клеток периферической крови (МНК ПК) здоровых доноров и клеточная линия меланомы мыши В16. МНК ПК выделялись из гепаринизированной венозной крови здоровых доноров путем центрифугирования в градиенте плотности фиколл- урографина. Клетки культивировались в питательной среде RPMI-1640, содержащей 0,3\% $\mathrm{L}$-глутамина, 50 мкг/мл гентамицина, 25 мкг/мл тиенама и $10 \%$ 
инактивированной сыворотки FCS. Для оценки жизнеспособности клетки культивировали в присутствии различных концентраций ГК в течение 72 ч в 96-луночном плоскодонном планшете в количестве 10 тыс/лунка для клеточных линий и 100тыс/лунка для МНК ПК. В качестве негативного контроля использовали DMSO, обладающего токсическим действием на все виды клеток. Через 72 ч добавляли 10 мкл WST-1 в каждую лунку, результаты оценивали спектрофотометрически на длине волны 450 нм (референс 620 нм). Статистическую обработку результатов исследования проводили, вычисляя медиану (Me), 25-ю и 75-ю процентиль (LQ, HQ), и представляли в виде Ме (LQ, HQ). Различия между группами оценивали с помощью непараметрического U-критерия Манна - Уитни, достоверными считали результаты при $\mathrm{p}<0,05$.

В результате было получено, что ГК снижает жизнеспособность клеток линии RPMI 2650 в высокой концентрации (500 мг/мл), в остальных концентрациях (100 мкг/мл и ниже) ГК не влияла на жизнеспособность данных клеток (Табл. 1). Было показано, что ГК не снижает жизнеспособность МНК ПК во всех исследуемых концентрациях. Более того, наблюдалось повышение жизнеспособности МНК ПК при добавлении ГК в концентрации 10 мкг/мл, что, возможно, связано с активацией клеток и усилением их пролиферативной активности в присутствии ГК. Также было обнаружено, что в концентрации 100 мкг/мл и 1 мкг/мл имеется тенденция по повышению жизнеспособности клеток, однако полученные результаты не являются достоверными. В случае с клеточной линией В16, ГК способна повышать жизнеспособность данных клеток, по-видимому, усиливая пролиферацию данных клеток, только в высокой концентрации 0,5 мкг/мл (Табл. 1). Следовательно, ГК обладает низкой токсичностью для различных видов клеток, что согласуется с данными литературы.

\section{Таблица 1}

\section{Влияние различных концентраций глицирризиновой кислоты на} жизнеспособность различных культур клеток, \%

\begin{tabular}{|c|c|c|c|}
\hline & МНК ПК & RPMI-2650 & В16 \\
\hline 0 мкг/мл & $100,0(95,4-104,1)$ & $100(98,3-103,9)$ & $97,2(97,9-103,6)^{*}$ \\
\hline 1 мкг/мЛ & $104,1(99,3-115,1) \#$ & $94,1(83,6-99,9)$ & $94,1(93,8-97,9)$ \\
\hline 10 мкг/мл & $106,1(103,2-117,6)^{*}$ & $99,5(96,2-105,7)$ & $97,3(91,0-101,9)$ \\
\hline 100 мкг/мл & $108,4(92,2-142,4) \#$ & $96,4(67,8-100,2)$ & $93,5(91,5-96,6)$ \\
\hline 500 мкг/мл & $108,0(96,6-133,2)$ & $81,2(79,9-93,3)^{*}$ & $117,5(101,9-146,1)$ \\
\hline
\end{tabular}


Примечания: * достоверные различия $(\mathrm{p}<0,05)$ по сравнению с контролем (концентрацией 0 мкг/мл); \# тенденция $(\mathrm{p}<0,07)$ по сравнению с контролем.

Исследование выполнено при финансовой поддержке РФФИ в рамках научного проекта № 20-315-70039.

\section{Список литературы}

1. Yang Y, Shi Q, Liu Z, Li RJ, Pan PW, Hou YY, Lu WG, Bai G.The synergistic anti-asthmatic effects of glycyrrhizin and salbutamol. Acta Pharmacol Sin. 2010 Apr; 31(4):443-9.

2. М.А. Моренко Обоснование целесообразности использования препаратов глицирризиновой кислоты в комплексной терапии бронхиальной астмы у детей // Медицина и экология. 2010. № 2 (55). С. 97-100.

3. Cavone L, Cuppari C, Manti S, Grasso L, Arrigo T, Calamai L, Salpietro C, Chiarugi A. Increase in the Level of Proinflammatory Cytokine HMGB1 in Nasal Fluids of Patients With Rhinitisand its Sequestration by Glycyrrhizin Induces Eosinophil Cell Death. Clin Exp Otorhinolaryngol. 2015 Jun; $8(2): 123-8$.

4. Li XL, Zhou AG. Evaluation of the immunity activity of glycyrrhizin in AR mice.

5. Molecules. 2012 Jan 12;17(1):716-27.

6. Ma C, Ma Z, Liao XL, Liu J, Fu Q, Ma S. Immunoregulatory effects of glycyrrhizic acid exerts anti-asthmatic effects via modulation of Th1/Th2 cytokines and enhancement of CD4(+)CD25(+)Foxp3+ regulatory $\mathrm{T}$ cells in ovalbuminsensitized mice. J Ethnopharmacol. 2013 Jul 30; 148(3):755-62.

7. Wu Q, Tang Y, Hu X, Wang Q, Lei W, Zhou L, Huang J. Regulation of Th1/Th2 balance through OX40/OX40L signalling by glycyrrhizic acid in a murine model of asthma. Respirology. 2016 Jan; 21(1):102-11.

8. Han S, Sun L, He F, Che H.Anti-allergic activity of glycyrrhizic acid on IgE-mediated allergic reaction by regulation of allergy-related immune cells. Sci Rep. 2017 Aug 3; 7(1):7222.

9. Chen D, Bellussi LM, Cocca S, Wang J, Passali GC, Hao X, Chen L, Passali D. Glycyrrhetinic acid suppressed hmgb1 release by up-regulation of Sirt6 in nasal inflammation. J Biol Regul Homeost Agents. 2017 Apr-Jun; 31(2):269-277. 
10. Fouladi S, Masjedi M, Ghasemi R, G Hakemi M, Eskandari N. The In Vitro Impact of Glycyrrhizic Acid on CD4+ T Lymphocytes through OX40 Receptor in the Patients with Allergic Rhinitis. Inflammation. 2018 Jul 12. doi: 10.1007/s10753-018-0813-8

11. Wang Y., Boxin Zhao, Shengqi Wang, Qianying Liang, Yun Cai, Fuheng Yang \&Guofeng Li (2016) Formulation and evaluation of novel glycyrrhizic acid micelles for transdermal delivery of podophyllotoxin, Drug Delivery, 23:5, $1623-1635$ 